Thorax (1963), 18, 361

\title{
Severe irreversible airways obstruction without emphysema
}

\author{
T. SIMPSON, B. HEAR D, A N D J W L A W S \\ From Chase Farm Hospital, Enfield, and the Postgraduate Medical School of London
}

\begin{abstract}
A combination of clinical, radiological, and physiological changes commonly called 'emphysema' is so often confirmed at necropsy that it is interesting to find that some patients whose condition seemed to be clinically indistinguishable from emphysema during life did not in fact have it. In a large series of patients who were intensively studied during life in a clinic for 'emphysematous' patients, 22 died between December 1958 and February 1960. A careful necropsy study was made in all, and three showed little or no evidence of emphysema. This paper is concerned only with those three patients, who are reviewed to see if emphysema could have been excluded during life.
\end{abstract}

\section{METHODS}

PHYSIOLOGICAL The ventilatory capacity of the lungs was determined in patient 1 and partly in patient 2 by measuring the volume of air expired in 15 or 20 seconds during maximum voluntary effort. In patient 3 and partly in patient 2 the forced expiratory volume and maximum expiratory flow rate were measured using a kymograph and special spirometer (Bernstein, D'Silva, and Mendel, 1952). The average of three readings was taken. The arterial blood $\mathrm{CO}_{2}$ content and $\mathrm{O}_{2}$ saturation were determined using the manometric Van Slyke method (Van Slyke and Neill, 1924). The $p H$ was measured at room temperature on a Cambridge $p \mathrm{H}$ meter, using the Stadie electrode system, after standardization to $p \mathrm{H} 4$ and 7 buffers. The observed $p \mathrm{H}$ was corrected to $38^{\circ} \mathrm{C}$. by using Rosenthal's factor (1948). Arterial $\mathrm{CO}_{2}$ tension was calculated from the total $\mathrm{CO}_{2}$ content of the plasma and the $p \mathrm{H}$ using the Henderson-Hasselbach equation. The fractional uptake of $\mathrm{CO}$ by the lungs was measured according to the method of MacNamara, Prime, and Sinclair (1959).

Pathological Lung slices were prepared, usually from the left lung, and the middle slice was lightly impregnated with barium sulphate and examined by the dissecting microscope (Heard,
$1958 ; 1960)$. The percentage of a slice that was emphysematous was estimated as described previously (Heard, 1962; Laws and Heard, 1962).

RADIOLOGICAL A series of postero-anterior and lateral chest radiographs of each patient taken over a period of several years was examined without a knowledge of the clinical and pathological findings.

The radiological criteria for diagnosing emphysema have been described (Laws and Heard, 1962). The most important were a reduction in the number and calibre of the peripheral pulmonary arteries, often with an increased transradiancy of the background due to a local destruction of the vascular bed.

THE THREE PATIENTS

PATIENT 1 This man, aged 56, had been kyphotic since childhood and there was a family history of chest disease. Although he had suffered from winter bronchitis since youth, it was not until 1942 that he had his first severe attack. In succeeding winters the attacks became progressively worse, and in 1949 he was admitted to hospital because of a severe pneumonia, when oxygen caused $\mathrm{CO}_{2}$ narcosis. Before 1952 he was a self-employed composition floor layer and afterwards a press tool operator, but following this pneumonia his breathlessness increased so much that in 1952 he was registered as a disabled person.

Swelling of the ankles, increasing dyspnoea, and drowsiness caused him to stop work before admission to Chase Farm Hospital in January 1955. He was severely orthopnoeic, very drowsy, and twitching. On examination he was moderately kyphotic, the intensity of the breath sounds was good, and there were accompanying moist sounds. Physical signs associated with overdistension of the lungs were not present, and the heart sounds were readily heard in the mitral area. The descent of the diaphragm on deep inspiration as determined by tidal percussion was much reduced. The blood pressure was $160 / 90 \mathrm{~mm}$. $\mathrm{Hg}$. Examination of the fundus oculi showed papilloedema.

Convalescence after January 1955 was stormy. punctuated by three episodes of severe hypoxia and 
semi-coma which came on suddenly and for which no cause could be found. In one such episode he was quite alert on the evening preceding it. Next morning he was just rousable and the arterial $\mathrm{O}_{2}$ saturation was $45 \%, \mathrm{PcO}_{2} 65.5 \mathrm{~mm}$. $\mathrm{Hg}$, and $\mathrm{pH} 7.27$. He had a profuse rectal haemorrhage at this time for which no cause could be found.

He later developed swelling of the ankles which was resistant to diuretics and tended to recur to a greater or lesser degree over the next three years. He was admitted in December 1957 because of a chest infection. Whilst in hospital his condition deteriorated and tracheostomy had to be done. He was discharged after seven weeks, but the ankle swelling persisted.

In the summer of 1958 he was much improved and able to help with the house decorating. He could dress in reasonable comfort.

According to his sister-in-law, his general condition deteriorated after September 1958, and he was admitted in November of that year because of a chest infection. He was extremely ill, cyanosed, orthopnoeic but alert, and there was slight ankle swelling. Coarse crackling sounds were heard at both lung bases. He could tolerate full oxygenation without mental change. No pathogens were cultured from the purulent sputum. After two weeks he was much improved but in the third week his condition again deteriorated. Antibiotics were without effect, and on the fourth day after the recrudescence of the chest infection he died suddenly one hour after talking to the night nurse. The electrocardiogram showed a normal tracing in 1955, grade 1 right ventricular hypertrophy in 1956, and grade 2 in 1957 and 1958 (Goodwin and Abdin, 1959).

Radiology There was an angular mid-dorsal kyphosis probably due to a juvenile osteochondritis of D.8, 9, and 10. This made assessment of the heart size difficult but it appeared to be moderately enlarged. None of the criteria of emphysema was found. Indeed the main pulmonary arteries and their second and third division branches were enlarged giving an appearance of pulmonary plethora (Fig. 1). We thought that these changes became more severe when the arterial $\mathrm{O}_{2}$ saturation was reduced and the $\mathrm{CO}_{2}$ tension increased.

Pathology The trachea and main bronchi contained some moderately viscid mucus, partly yellow. The left lung $(800 \mathrm{~g}$.) was examined unfixed. Over the apex and in a few sites elsewhere there were dense adhesions. There were no bullae. In the upper lobe there was a trace of pigmented focal emphysema, and the lower lobe showed mild bronchopneumonia. There was no bronchiectasis. Small bronchi contained thin mucin. At the left apex was an old scar, $1.5 \mathrm{~cm}$. deep, showing small cystic bronchioles but no calcification. The right lung was pressurefixed (volume 2,890 ml.). Over the whole of the lower lobe there were dense adhesions. The antero-
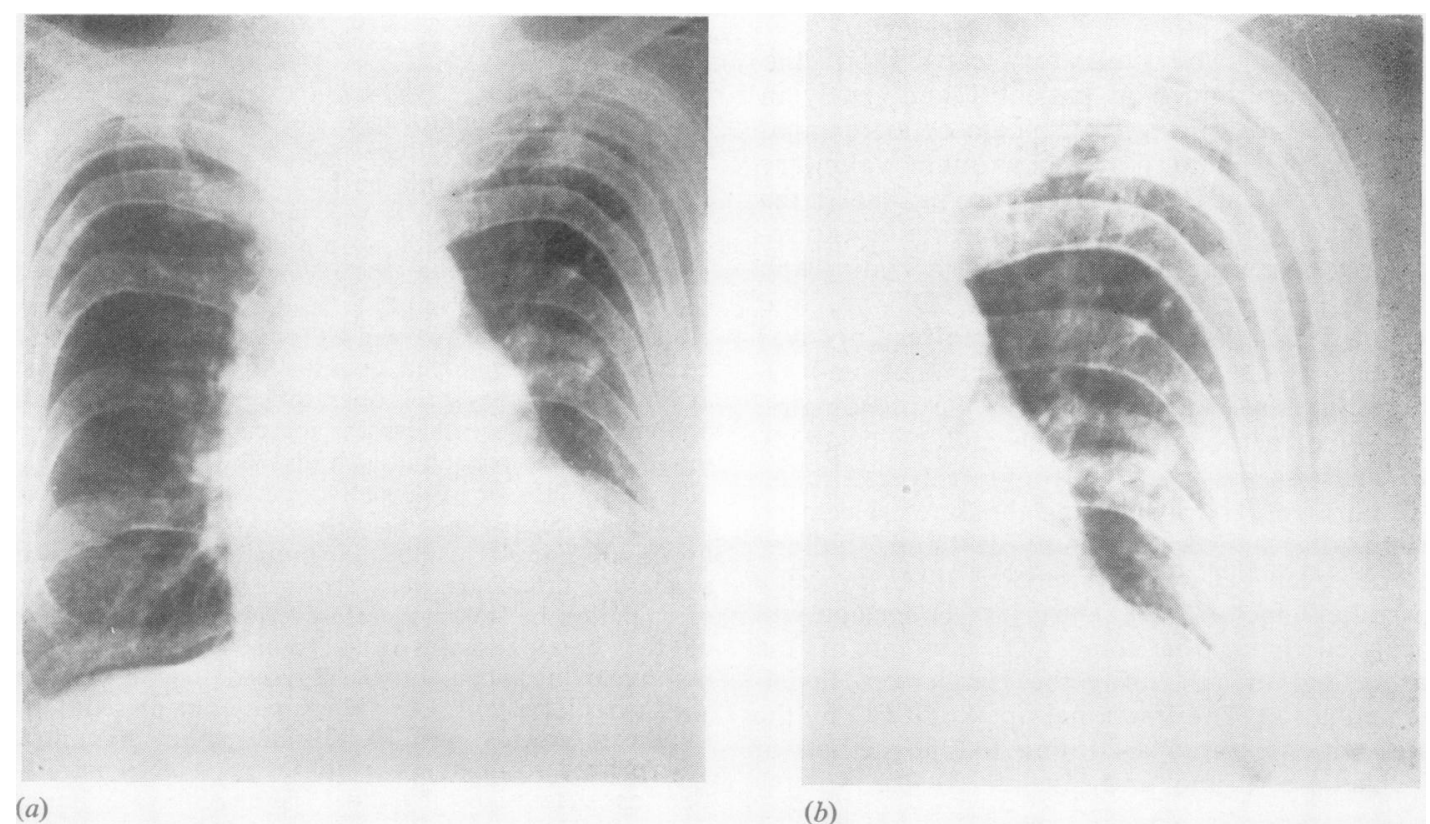

fIG. 1. Patient 1. (a) Anterior chest film showing a large heart with a large main pulmonary artery. Thoracic deformity made exact assessment of heart size difficult. (b) Enlarged view of left upper zone showing a normal peripheral arterial pattern. 


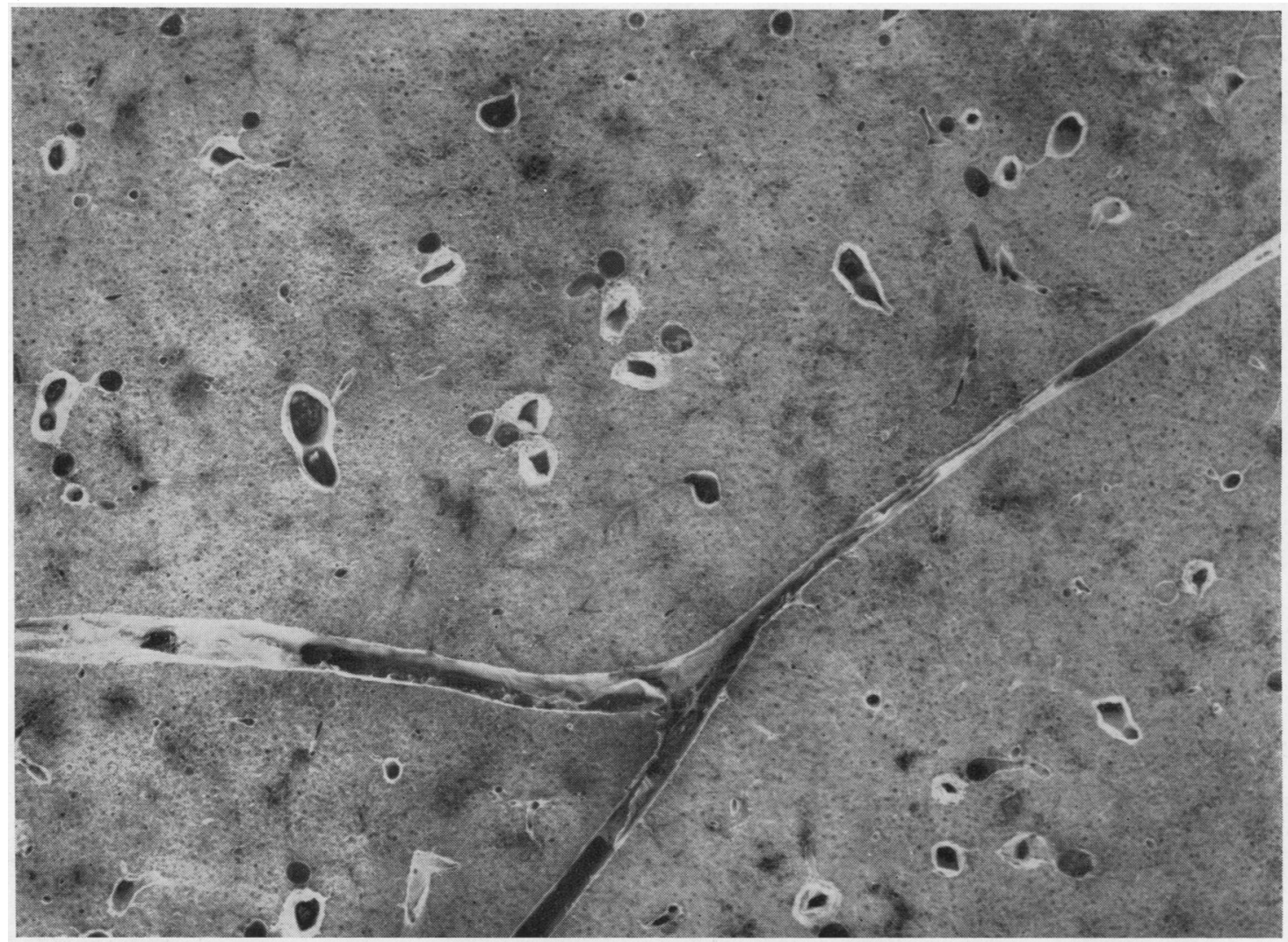

FIG. 2. Patient 1. Centre of slice of right lung showing almost complete absence of emphysema. Barium sulphate impregnation, $\times 1 \cdot 5$.

posterior diameter was increased and the height decreased owing to the kyphosis. There were no bullae. A slice impregnated with barium sulphate revealed only a trace of centrilobular emphysema in the upper lobe near an apical scar. Most of the slice showed no emphysema (Fig. 2). In the anterior apical segment was a recanalized thrombus in a mediumsized pulmonary artery.

Histology Various bronchi were congested, and the glands showed mucous conversion although they were not enlarged. Bronchial muscle did not appear increased in amount. Sections of the upper lobes showed occasional fibrous thickening of the walls of small groups of alveoli as well as a trace of focal emphysema.

Assessment of emphysema in the right lung Less than $5 \%$ of the area of the slice was affected.

Heart The heart weighed $700 \mathrm{~g}$. The right ventricular wall was hypertrophied to $5.5 \mathrm{~mm}$. in the outflow pathway, and the left ventricular wall was hypertrophied to $18 \mathrm{~mm}$. The liver showed chronic venous congestion microscopically.

Cause of death Respiratory failure with insignificant emphysema; cor pulmonale; mild bronchopneumonia.
PATIENT 2 This man was aged 46 when first seen in 1955 in the out-patient clinic, and he had had bronchitis since an attack of pneumonia at the age of 18. Apart from chest infections he had little sputum. On examination he was a well-nourished, cyanosed man with injected sclerae, and was drowsy and orthopnoeic. The veins of the fundus oculi were dilated, tortuous, and dark. The accessory muscles of respiration were not in evidence, and physical signs associated with overdistension of the lungs were not prominent. There was a slight reduction in the intensity of the breath sounds at the lung bases, and there were many accompanying moist sounds. The heart sounds were normal and more readily audible in the epigastrium. Blood pressure was $150 / 80 \mathrm{~mm}$. $\mathrm{Hg}$. He complained of ankle swelling for the preceding two months but none was found on admission.

Between the years 1955 and 1959 inclusive he was admitted to hospital five times, all in the winter months. Each time he was extremely cyanosed and drowsy, but none of the infections caused anxiety. Between the attacks he made light of his dyspnoea, but it was severe because he could only work at a slow pace in the summer, and became extremely breathless on bending. His daughter confirmed that 
for 18 months before his death he had been much worse; he had fallen asleep easily, had become forgetful and irritable, and had become blue on the slightest exertion. It was all the more surprising therefore that he had been able to play an occasional 18 holes of golf on a fairly flat course at his own pace in the summer and autumn of 1956.

The electrocardiogram was normal from 1955 to January 1959 when it showed a dominant R in VR and a dominant S in V5 (grade 3 ).

His last admission was in May 1959, when he complained of left-sided pleuritic pain, shortness of breath, and purulent sputum. On examination he was very ill, orthopnoeic, twitching, cyanosed, pyrexial, and coughing up a large quantity of purulent sputum from which $\boldsymbol{H}$. influenzae was cultured. His legs were swollen for the first time since 1955, and he died after four days.

Radiology None of the criteria of emphysema was found. There was moderate enlargement of the right ventricle (Fig. 3a). The main pulmonary arteries were enlarged and there was pulmonary plethora particularly noticeable in the upper zones where, in addition, dilated pulmonary veins could be clearly seen (Fig. 3b). In March 1956 there had been evidence of a right basal pneumonia and in April 1959 of a left upper lobe abscess (not illustrated).

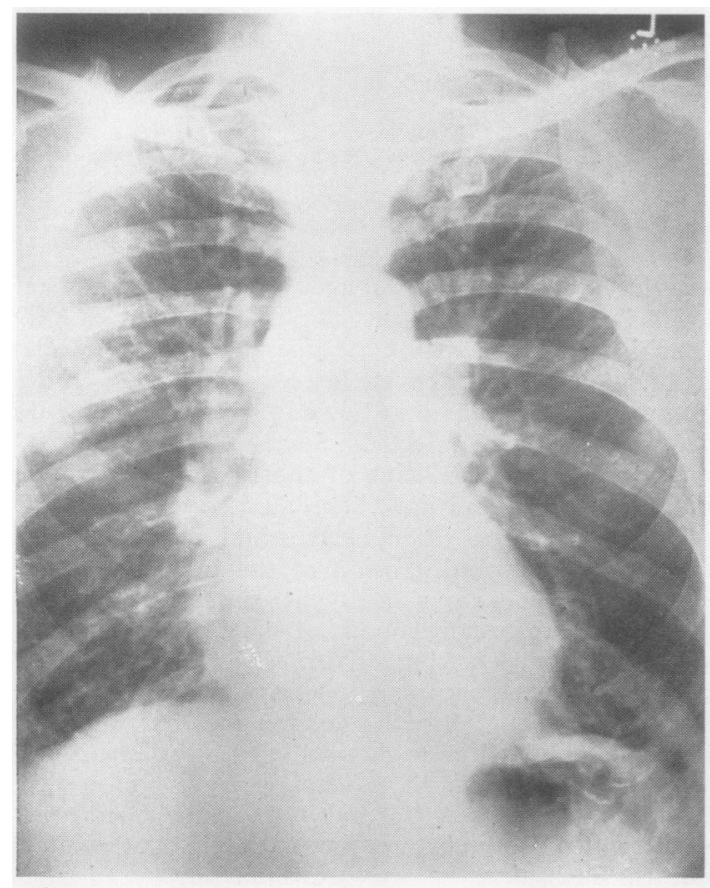

(a)
Pathology The trachea was congested in the lower half and contained a little mucopus. All bronchi contained mucopus in large amounts. The left lung $(860$ g.) was pressure fixed (volume $3,400 \mathrm{ml}$.). Over the anterior segment of the upper lobe there were dense adhesions but few elsewhere. There were no bullae. The main pulmonary artery at the hilum was distended and partly obstructed by a large thrombus. A slice of lung impregnated with barium sulphate showed a number of features. There were patches of diffuse (panacinar) emphysema near the pleura down the back of the lower lobe and there was some diffuse and a trace of unpigmented centrilobular emphysema near the front of the upper lobe (Fig. 4). Many thrombi were distributed in the pulmonary arteries of both lobes, and air spaces in the infarcted posterior half of the upper lobe were filled with blood.

Between the apical and anterior segments of the upper lobe was an abscess cavity, $4 \mathrm{~cm}$. in diameter, with a white wall and ragged inner aspect (Fig. 5). In the lower lobe and lingula there was bronchiectasis. the bronchial walls being thin and slightly sacculated. The right lung $(540$ g.) was examined unfixed. Most of the lower lobe was covered by adhesions. The right main pulmonary artery was partly blocked by a thrombus which extended down most segmental arteries. In the apical and anterior basal segments of

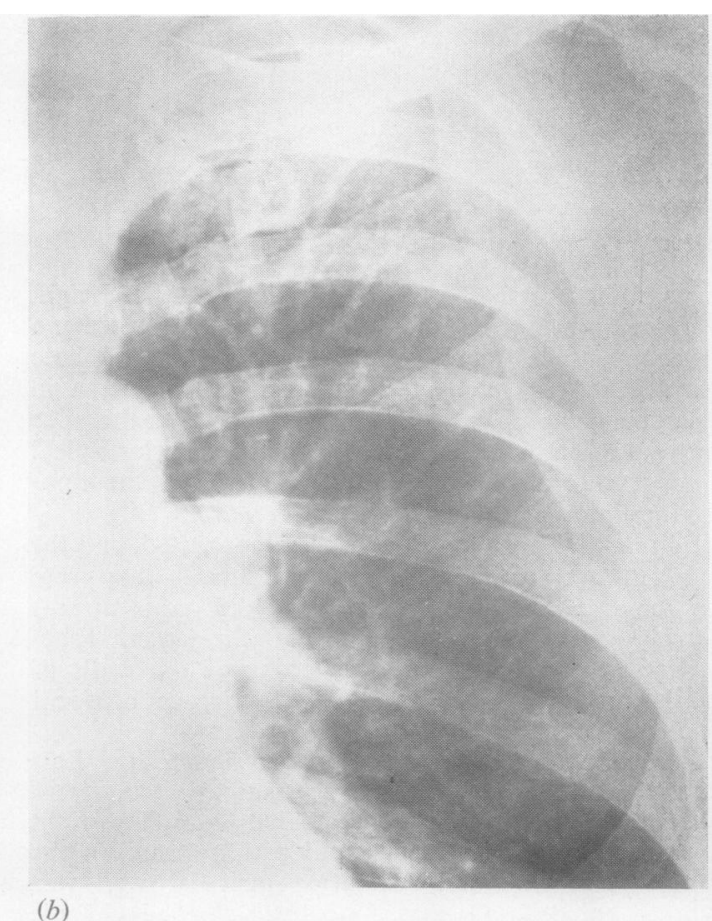

(b)

FIG. 3. Patient 2. (a) Anterior chest film showing moderate cardiac enlargement with enlargement of the main pulmonary arteries and the hilar branches. (b) Enlarged view of the left upper zone showing normal peripheral pulmonary arterial pattern. 


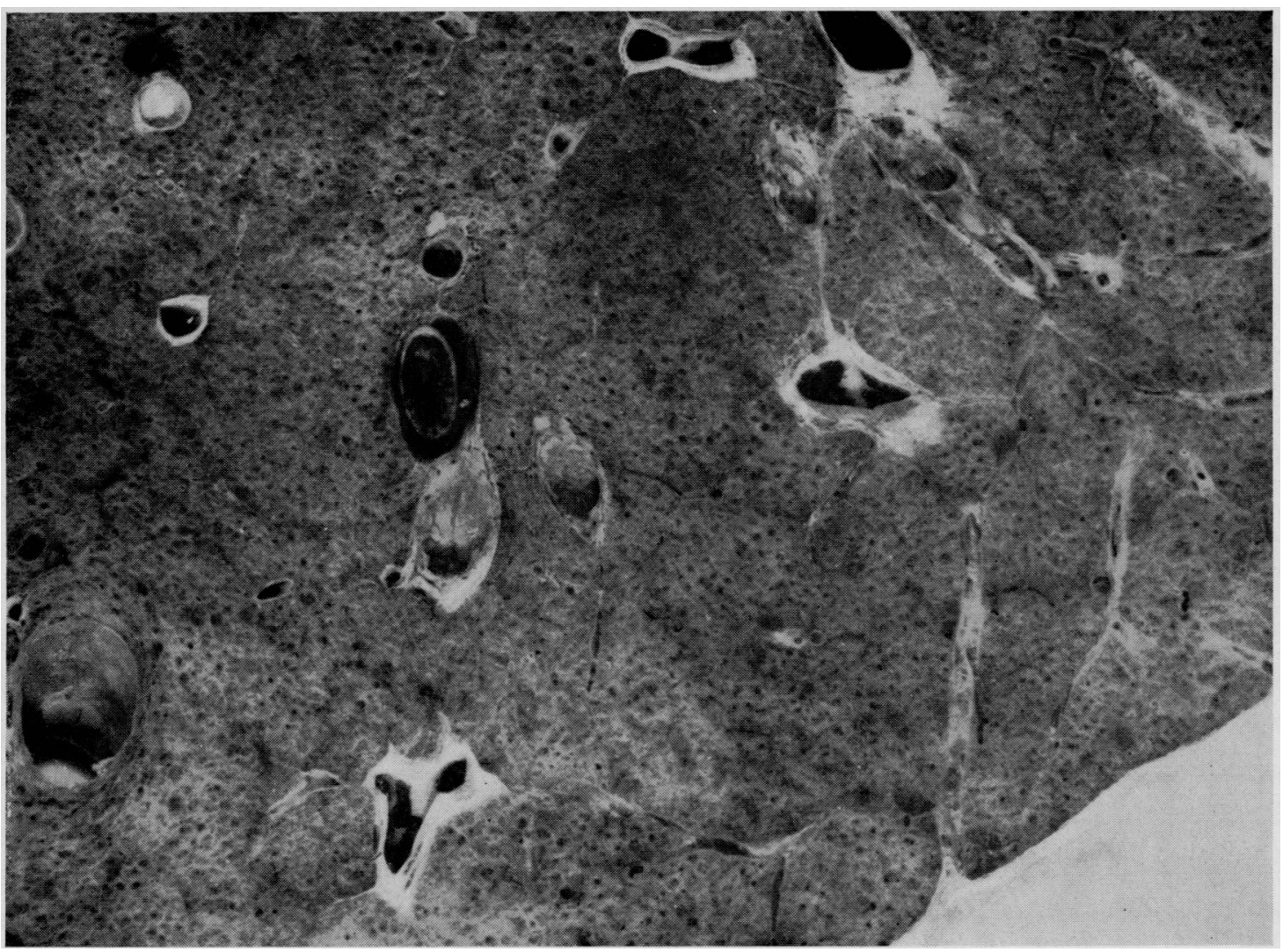

FIG. 4. Patient 2. Lower part of slice of left lung showing thrombi in pulmonary arteries, bronchiectasis (lower left quadrant), and only a little panacinar emphysema in this region. Barium sulphate impregnation, $\times 1 \cdot 7$.

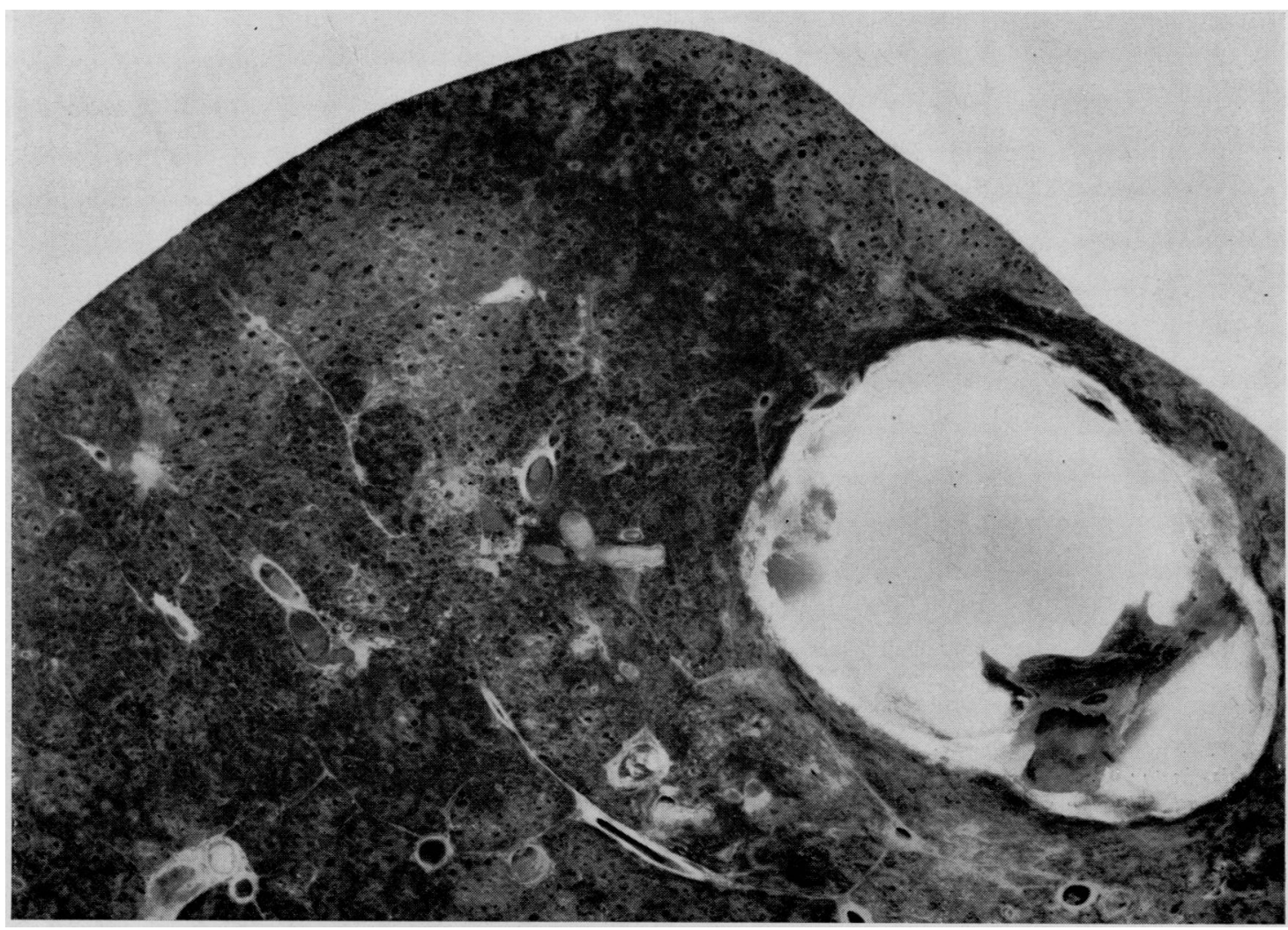

FG. 5. Patient 2. Upper part of slice of left lung showing large aspergilloma cavity, thrombi in pulmonary arteries, mucus in bronchi, and only a trace of emphysema. Barium sulphate impregnation, $\times 1.6$. 
the lower lobe were recent infarcts. All the bronchi were slightly dilated, and one in the posterior basal segment had a saccular dilatation. $1.5 \mathrm{~cm}$. in diameter. The only emphysema found in the unfixed lung was a trace of the centrilobular variety in the posterior segment of the upper lobe.

Histology Various bronchi showed acute inflammation of the mucosa. Goblet cells were prominent in places. Mucous ducts were normal or slightly dilated, and some were surrounded by lymphocytes. Some glands were enlarged, and all showed mucous conversion. Bronchial muscle was hypertrophied. The saccular bronchus in the right posterior basal segment showed no inflammation, and glands and cartilage were absent. The abscess was an aspergilloma. Large arteries showed atheroma and thrombi. Small arteries showed no evidence of recurrent pulmonary embolism.

Assessment of emphysema In the left lung $25 \%$ of the area of the slice was affected.

Heart The heart weighed $440 \mathrm{~g}$. The weight of the free wall of the right ventricle was $120 \mathrm{~g}$.. indicating hypertrophy (normal maximum weight $80 \mathrm{~g}$.).

Cause of death Acute suppurative bronchitis; pulmonary artery thrombosis; aspergilloma; terminal respiratory failure.

PATIENT 3 This lady, aged 64, had had bronchitis for 37 years with increasing shortness of breath: there was no family history of chest trouble. The ankles were swollen when she was ill in 1955, and again in 1957 when she admitted to episodes of 'blueness and confusion'. She was aged 64 when first seen after admission to Chase Farm Hospital in January 1958 because of a neglected chest infection. Her appearance suggested a superior venal caval obstruction. She was disorientated and deeply cyanosed, and the neck veins were extremely engorged. The veins of the fundus oculi were engorged and very dark in colour. There was slight ankle swelling which increased but was absent when she was discharged six weeks later. Radiologically the heart was enlarged. Blood pressure was $140 / 80 \mathrm{~mm}$. $\mathrm{Hg}$. Electrocardiograms were within normal limits and remained so until her death.

In June 1958 she felt better than she had done for three years. Her blood pressure was then 220/125; presumably the stress of the severe hypoxia had been responsible for the previous low figure. Apart from a mild infection during the fog of November 1958 she remained well, and when seen in the out-patient clinic in July 1959 she declared that her breathing had improved to such an extent that she led an almost normal life and felt more alert mentally. However. she was obese, squat, ruddy-complexioned, and cyanosed, and though her breathing was not obviously laboured at rest, it became so on moderate exertion when she also became very blue. The physical signs associated with overdistension of the lungs were not prominent. On auscultation the breath sounds at the

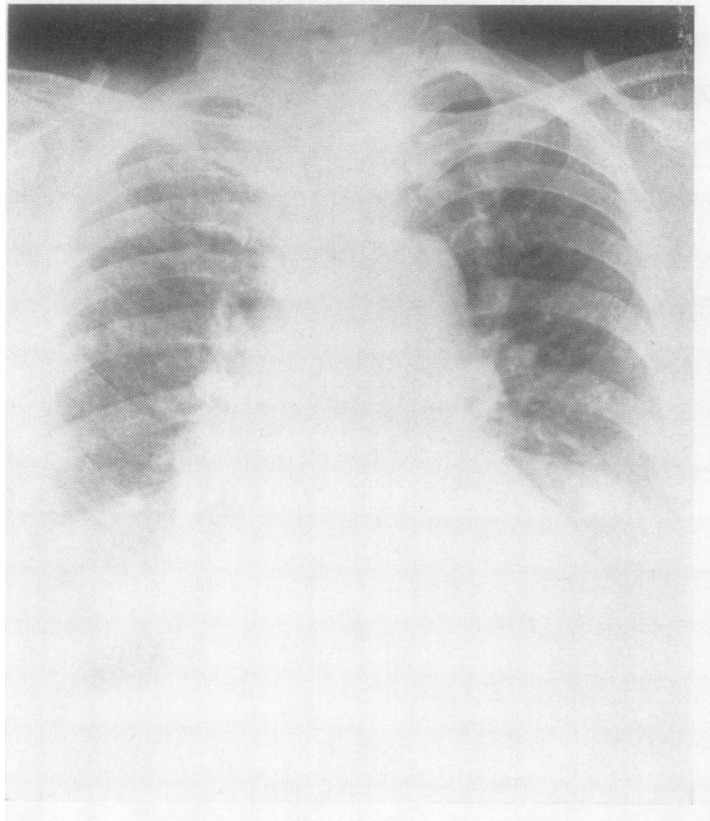

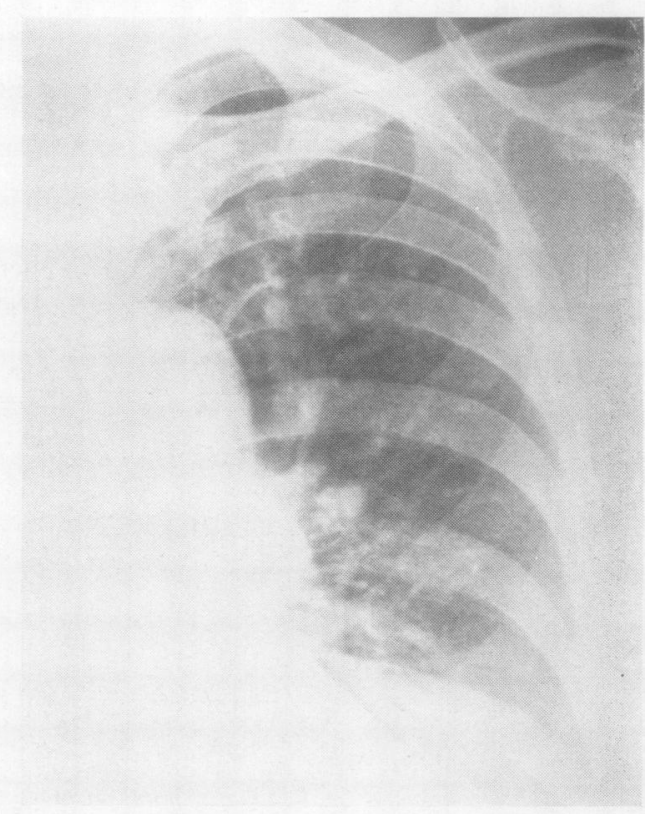

(b)

FIG. 6. Patient 3. (a) Anterior chest film showing moderate cardiac enlargement, dilated aorta, enlarged pulmonary arteries in the hila, and pulmonary plethora in the lower zone. (b) Enlarged view of the left upper zone showing normal peripheral pulmonary arterial pattern. 


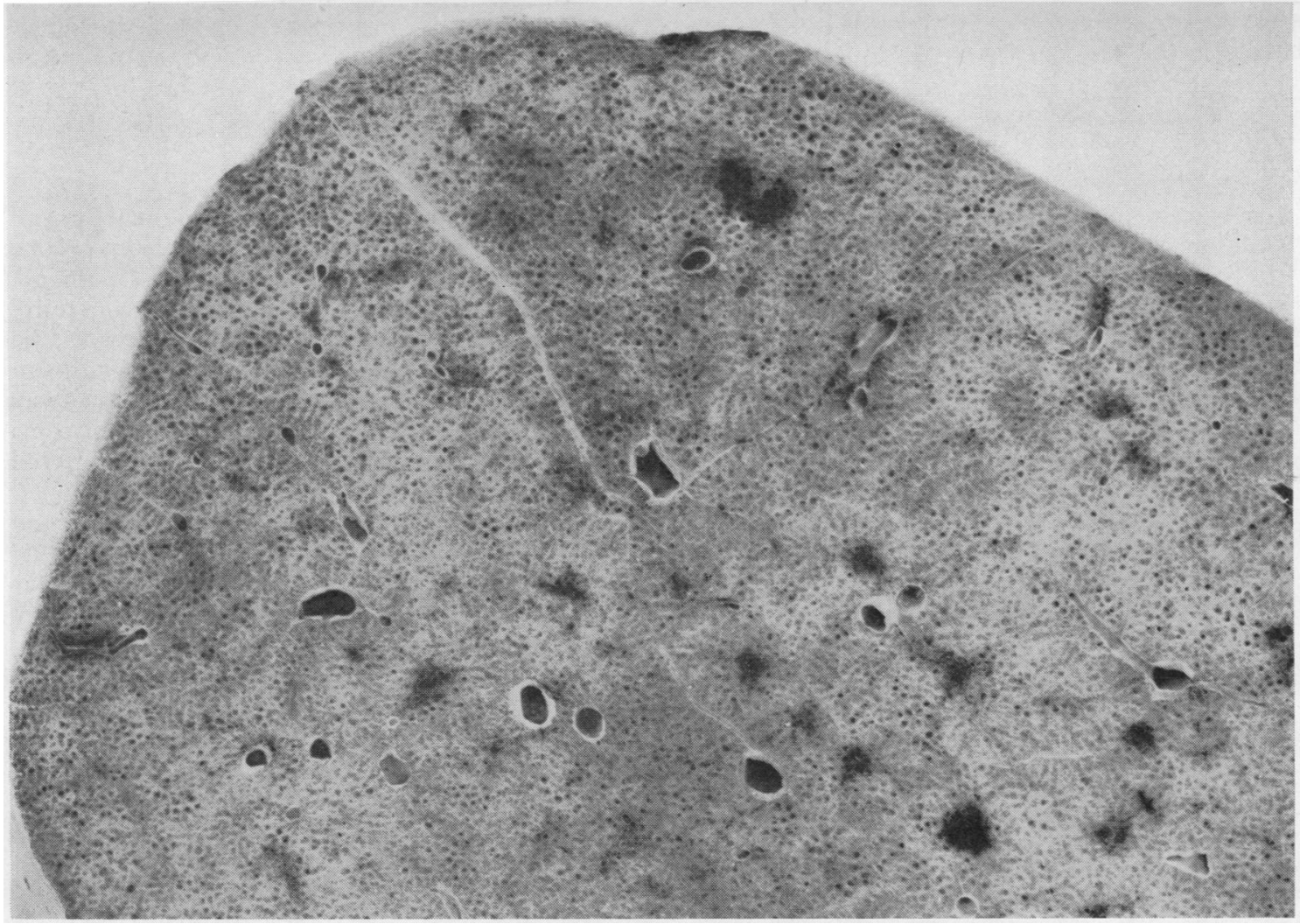

FIG. 7. Patient 3. Upper part of slice of left lung showing absence of emphysema. Barium sulphate impregnation, $\times 1 \cdot 6$.

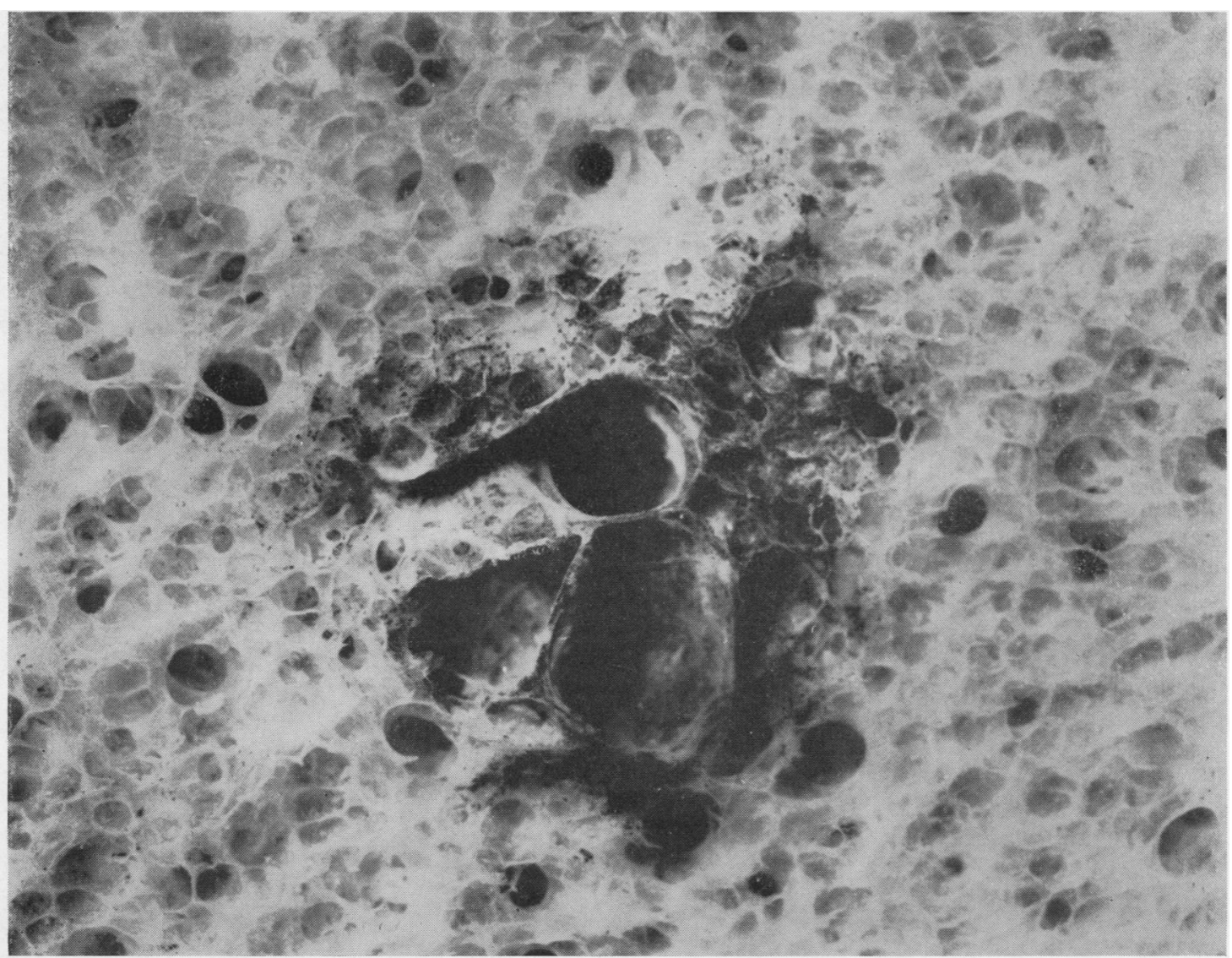

FIG. 8. Patient 3. Higher magnification of left lung showing a small cluster of pigmented, dilated bronchioles, i.e., focal emphysema, but otherwise normal air spaces. Barium sulphate impregnation, $\times 19$. 
lung bases were diminished in intensity and there were many moderate crackling sounds.

She was re-admitted in January 1960 after being ill at home for five days. Her condition was identical with that in January 1958, though there was no ankle swelling. Unresponsive to treatment she died after four days.

Radiology None of the criteria of emphysema was found. Instead there was pulmonary plethora, both arterial and venous. The heart was moderately enlarged with unfolding of the aorta (Fig. 6).

Pathology The trachea was normal. The left lung (375 g.) was pressure fixed. No adhesions were present and no bullae. A barium sulphate impregnated slice, apart from a trace of focal emphysema (Fig. 8), was normal (Fig. 7). The basal bronchi were slightly dilated. The right lung (535 g.) was examined unfixed. It showed dense adhesions confined to the lower lobe. There were no bullae. No certain emphysema was identified in the fresh specimen. In the posterior basal segment was an old, partly calcified, tuberculous focus, and in a hilar lymph node there was a similar lesion. The bronchi were dilated and the walls were thin; this applied especially to the lower lobe.

Histology Various bronchi were somewhat dilated but revealed no pathological changes in the mucosa, glands, ducts, muscle, elastic tissue, or cartilage. One non-respiratory bronchiole showed goblet-like hyperplasia but others were normal. Large pulmonary arteries were atheromatous but the smaller arteries were normal. In the centre of the lower lobe a medium-sized pulmonary artery contained a recent thrombus.

Assessment of emphysema In the left lung less than $5 \%$ of the area of the slice was affected.

Heart The heart weighed $560 \mathrm{~g}$. The wall of the right ventricle in the outflow pathway was hypertrophied to $6 \mathrm{~mm}$. and the left to $19 \mathrm{~mm}$.

Cause of death Acute gastric erosions with haemorrhage; hypertension; acute respiratory failure.

\section{DISCUSSION}

In all three patients the tests of ventilatory function indicate gross impairment (Table I). Thus in patients
1 and 2 the maximum breathing capacity and voluntary ventilation are reduced to almost one fifth of the predicted normal (Baldwin, Cournand, and Richards, 1948) and in patient 3 to one third. This measurement was largely uninfluenced by the inhalation of a bronchodilator. The impairment therefore is largely due to irreversible airway obstruction. The blood gas measurements at some time in all three patients show a raised arterial $\mathrm{CO}_{2}$ tension and reduced $\mathrm{O}_{2}$ tension, implying alveolar hypoventilation. Using these values and the $\mathrm{O}_{2}-\mathrm{CO}_{2}$ diagram of Fenn, Rahn, and Otis (1946), it was found that the approximate alveolar to arterial oxygen tension difference was $30 \mathrm{~mm}$. $\mathrm{Hg}$ or more (normal difference $9 \mathrm{~mm}$. Hg; Comroe, Forster, Dubois, Briscoe, and Carlsen (1962)) in every study (Table II). This gradient implies considerable disturbance of the ventilation/perfusion balance and possibly some reduction in the diffusing capacity. The measurement of fractional uptake of $\mathrm{CO}$ in patient 3 supports this suggestion.

The diffusing capacity of the lungs is a measure of the total effective blood/gas interface, and it falls if there is an alteration in the regional lung ventilation such as may occur in asthma or bronchitis. A single determination therefore cannot assess any permanent lung damage. The percentage uptake of $\mathrm{CO}$ by the lungs in patient 2 was found to be within the normal range as established by MacNamara et al. (1959), but on two occasions that of patient 3 was reduced to

T A B LE I I

APPROXIMATE ALVEOLAR:ARTERIAL $\mathrm{O}_{2}$ TENSION DIFFERENCES

\begin{tabular}{cllll} 
Case & Date & $\begin{array}{l}\mathrm{PAo_{2 }} \\
(\mathrm{mm} . \mathrm{Hg})\end{array}$ & $\begin{array}{l}\mathrm{PaO} \\
(\mathrm{mm} . \mathrm{Hg})\end{array}$ & $\begin{array}{l}\mathrm{PAO}-\mathrm{PaO} \\
(\mathrm{mm} . \mathrm{Hg})\end{array}$ \\
\hline 1 & 10.1 .58 & 95 & 42 & 53 \\
2 & 16.1 .59 & 75 & 45 & 30 \\
3 & 17.7 .59 & 95 & 60 & 35
\end{tabular}

$\mathrm{PAO}_{2}=$ alveolar $\mathrm{O}_{2}$ tension $\mathrm{PaO}_{2}=$ arterial $\mathrm{O}_{2}$ tension

T A B LE I

\begin{tabular}{|c|c|c|c|c|c|c|c|c|c|c|c|c|c|c|}
\hline \multirow[t]{2}{*}{ Case } & \multirow[t]{2}{*}{ Date } & \multicolumn{4}{|c|}{ Arterial Blood } & \multirow{2}{*}{$\begin{array}{l}F . E . V \cdot 1 \\
(l .)\end{array}$} & \multirow{2}{*}{$\begin{array}{l}F . V . C . \\
(l .)\end{array}$} & \multirow{2}{*}{$\underset{(\%)}{F . V . C .}$} & \multirow{2}{*}{$\begin{array}{l}\text { M.B.C. } \\
(l . ! \min .)\end{array}$} & \multirow{2}{*}{$\begin{array}{l}\text { M.E.F.R. } \\
\quad(\text { l. } \min .)\end{array}$} & \multirow{2}{*}{$\begin{array}{l}\text { Tidal } \\
\text { Volume } \\
(\mathrm{ml} .)\end{array}$} & \multirow{2}{*}{$\begin{array}{l}\text { Minute } \\
\text { Volume } \\
(l . \\
\text { min. })\end{array}$} & \multirow{2}{*}{$\begin{array}{l}C O \\
\text { Uptake } \\
(\%)\end{array}$} & \multirow{2}{*}{$\begin{array}{l}\text { Body } \\
\text { Surface } \\
\text { Area } \\
\left(\mathrm{m} .^{2}\right)\end{array}$} \\
\hline & & $\mathrm{p} H$ & $\begin{array}{l}\mathrm{Pco}_{2} \\
(\mathrm{mg})^{\mathrm{mg}}\end{array}$ & $\begin{array}{l}\mathrm{O}_{2} \\
\mathrm{Saturation}_{(\%)}\end{array}$ & $\begin{array}{l}P . C . V . \\
(\%)\end{array}$ & & & & & & & & & \\
\hline 1 & $\begin{array}{r}5.4 .55 \\
29.3 .56 \\
28.6 .57 \\
10.1 .58\end{array}$ & $\begin{array}{l}7 \cdot 43 \\
7 \cdot 42 \\
7 \cdot 41 \\
7 \cdot 42\end{array}$ & $\begin{array}{l}41 \\
45 \\
47 \\
46\end{array}$ & $\begin{array}{l}89 \\
81 \\
78 \\
78 \cdot 5\end{array}$ & $\begin{array}{l}44 \\
52 \\
48 \\
48\end{array}$ & & & & $\begin{array}{l}33 \\
27 \\
24 \\
26\end{array}$ & & & & & 1.95 \\
\hline 2 & $\begin{array}{r}27.5 .55 \\
4.9 .56 \\
2.8 .57 \\
16.1 .59\end{array}$ & $\begin{array}{l}7 \cdot 38 \\
7 \cdot 37 \\
7 \cdot 38 \\
7 \cdot 30\end{array}$ & $\begin{array}{l}61 \\
56 \\
53 \\
63\end{array}$ & $\begin{array}{l}64 \\
76 \\
81 \\
72\end{array}$ & $\begin{array}{l}54 \\
50 \\
69\end{array}$ & 0.5 & $0 \cdot 7$ & $71 \cdot 5$ & $\begin{array}{l}25 \\
16 \\
18 \\
17 \cdot 5\end{array}$ & 16 & 600 & & 50 & $1 \cdot 81$ \\
\hline \multirow[t]{2}{*}{3} & 5.3 .58 & $7 \cdot 42$ & 42 & 84 & 55 & \multirow[b]{2}{*}{$\begin{array}{l}0.6 \\
0.9\end{array}$} & \multirow[b]{2}{*}{$\begin{array}{l}0 \cdot 9 \\
1 \cdot 2\end{array}$} & \multirow[b]{2}{*}{$\begin{array}{c}56 \\
75\end{array}$} & \multirow[b]{2}{*}{$\begin{array}{l}21 \\
31.5\end{array}$} & \multirow[b]{2}{*}{${ }_{33}^{18}$} & & \multirow[b]{2}{*}{$5 \cdot 6$} & \multirow[b]{2}{*}{34} & \multirow[t]{2}{*}{$1 \cdot 77$} \\
\hline & $\begin{array}{l}17.7 .59 \\
\end{array}$ & $7 \cdot 39$ & 47 & 86 & 42 & & & & & & & & & \\
\hline
\end{tabular}


$34 \%$, a value within the same authors' 'emphysematous' range. Ogilvie (1959), studying the patterns of disturbed lung function in chronic obstructive vesicular emphysema, found that the diffusing capacity as determined by the breath-holding method (Ogilvie, Forster, Blakemore, and Morton, 1957) was normal in some patients and said 'There is therefore both pathological and physiological evidence to suggest that the clinical state of severe emphysema can exist in the absence of detectable damage to the alveolar or diffusing surface of the lung.'

Baldwin, Cournand, and Richards (1949) described in their combined cardiopulmonary insufficiency group the clinical history and radiological and physiological findings in a patient who was similar to our patients 1 and 2 ; they, too, were at a loss to explain the necropsy finding of nearly normal lungs. They attributed the hypoxia and hypercapnia to disturbed alveolar ventilation.

In all three there was evidence of right ventricular hypertrophy at necropsy.

It is generally thought that patients with chronic bronchitis, who develop severe airway obstruction which is irreversible, have 'emphysema'. If emphysema is taken to mean a functional state with an increased residual volume, then all such patients and all patients with asthma have emphysema. However, it has been suggested recently that emphysema should be diagnosed only in those who have irreversible changes with dilatation beyond the terminal bronchioles (W.H.O., 1961). This is what most clinicians assume to be present in cases such as those described in this paper, though we have shown that there may be very little or no emphysema present in the lungs. It is obviously useful to be able to distinguish those patients with irreversible changes from those without.

It is evident that none of the physiological tests which we have done, with the possible exception of the diffusing capacity, could help in the exclusion of emphysema during life in the three patients. In addition, although the lungs were radiologically normal, this does not serve to exclude emphysema since it is well known that extensive emphysema can be present although the lungs are radiologically normal (Laws and Heard, 1962).

Simpson (1958) suggested that there might be several clinical types of 'emphysema'. One easily recognizable type was that of the ruddy-faced, over-weight patient showing little evidence of respiratory distress at rest, who had chronic airway obstruction unrelieved by bronchodilators together with chronic hypoxia and hypercapnia, polycythaemia, and possibly ankle oedema. We suggest that such patients who, in addition, have a radiograph which shows a normal pulmonary arterial pattern or pulmonary plethora with possible cardiac enlargement and a normal fractional uptake of $\mathrm{CO}$ by the lungs are unlikely to have anatomical emphysema at necropsy. This opinion has been formed by us after a careful study of the clinical, radiological, and pathological findings in the 22 'emphysematous' patients as a whole.

The present investigation is incomplete but we hope to be able to report upon the diagnostic criteria when more material has been accumulated.

\section{SUMMARY}

Three patients are described who showed clinical and physiological features of chronic obstructive lung disease, though none showed radiological evidence of emphysema by established criteria. An insignificant degree of emphysema was found at necropsy using special methods of examination.

We are greatly indebted to Dr. J. J. Prendeville who performed the necropsies, to Dr. Moran Campbell for help in the preparation of the paper, and to Dr. C. M. Fletcher and Professor C. V. Harrison for reading the manuscript.

\section{REFERENCES}

Baldwin, E. de F., Cournand, A., and Richards, D. W. Jr. (1948) Pulmonary insufficiency. Medicine (Baltimore), 27, 243.

-1 (1949). Pulmonary insufficiency. Ibid., 28, 201.

Bernstein, L., D'Silva, J. L., and Mendel, D. (1952). The effect of the rate of breathing on the maximum breathing capacity determined with a new spirometer. Thorax, 7, 255.

Comroe, J. H. Jr., Forster, R. E., Dubois, A. B., Briscoe, W. A., and Carlsen, E. (1962). The Lung, 2nd ed. Year Book Medical Publishers, Chicago.

Fenn, W. O., Rahn, H., and Otis, A. B. (1946). A theoretical study of the composition of the alveolar air at altitude. Amer.J. Physiol., 146, 637.

Goodwin, J. F., and Abdin, Z. H. (1959). The cardiogram of congenital and acquired right ventricular hypertrophy. Brit. Heart J., 21, 523.

Heard, B. E. (1958). A pathological study of emphysema of the lungs with chronic bronchitis. Thorax, 13, 136.

(1960). Pathology of pulmonary emphysema. Methods of study. Amer. Rev. resp. Dis., 82, 792.

(1962). Fixation of the lung with respect to lung volume and air-space size. In Ciba Foundation Symposium on Pulmonary Structure and Function, p. 291. Churchill, London.

Laws, J. W., and Heard, B. E. (1962). Emphysema and the chest film: A retrospective radiological and pathological study. Brit. J. Radiol., 35, 750.

MacNamara, J., Prime, F. J., and Sinclair, J. D. (1959). An assessment of the steady-state carbon monoxide method of estimating pulmonary diffusing capacity. Thorax, 14, 166.

Ogilvie, C. (1959). Patterns of disturbed lung function in patients with chronic obstructive vesicular emphysema. Ibid., 14, 113. 
Ogilvie, C., Forster, R. E., Blakemore, W. S., and Morton, J. W. (1957). A standardized breath holding technique for the clinical measurement of the diffusing capacity of the lung for carbon monoxide. J. clin. Invest., 36,1 .

Rosenthal, T. B. (1948). The effect of temperature on the $p \mathrm{H}$ of blood and plasma in vitro. J. biol. Chem., 173, 25.

Simpson, T. (1958). Chronic bronchitis and emphysema. Tubercle (Lond.), 39, 307.

Van Slyke, D. D., and Neill, J. M. (1924). The determination of gases in blood and other solutions by vacuum extraction and manometric measurement. J. biol. Chem., 61, 523.

World Health Organization (1961). Chronic cor pulmonale. Report of an Expert Committee. W.H.O. Techn. Rep. Series, No. 213.

\section{ADDENDUM}

Since the end of this study in February 1960, a further 30 patients have died from the large series attending the 'emphysema' clinic. One of us (T.S.), using the criteria which have been described, predicted the absence of emphysema in three patients, and necropsy proved this to be correct. 